systems, on how the understanding of absolute risk can influence health professionals' decision making, and how interactive computers can assist patients in decision making, treatment preferences, and adherence to treatment schedules. ${ }^{11} 1819$ Developers of computer based clinical decision support systems should remember that as well as technological development, clinical understanding of the recommendations made by such systems is required.

We thank the 27 Avon practices for participating in this study and Shah Ebrahim for helpful comments on earlier drafts of this paper.

Contributors: The study was conceived and designed by TF, TP, and DS, with additional design input by AM. The computer based clinical decision support system was written by CM. Pilot work was done by AM, TF, and CM. Practices and patients were recruited by AM and TF. AM trained the health professionals in the use of the computer system and risk charts and collected the data. TP, AM, and TF performed the statistical analyses. AM, TF, and TP drafted the paper with contributions from DS and CM. $\mathrm{AM}, \mathrm{TF}$, and TP are the guarantors

Funding: NHS Wales Office of Research and Development, grant number RC016. TF is supported by an NHS R\&D primary care career scientist award.

Competing interests: None declared.

1 Jackson RT, Sackett DL. Guidelines for managing raised blood pressure. BMJ 1996;313:64-5.

2 Core Services Committee. Guidelines for the management of mildly raised blood pressure in New Zealand. Wellington: Ministry of Health, 1994.

3 Chatellier G, Blinowska A, Menard J, Degoulet P. Do physicians estimate

reliably the cardiovascular risk of hypertensive patients? Medinfo $1995 ; 8: 876-9$
4 Grover S, Lowensteyn I, Esrey K, Steinert Y, Joseph L, Abrahamowicz M Do doctors accurately assess coronary risk in their patients? Preliminar results of the coronary health assessment study. BMJ 1995;310:975-8.

5 Hunt D, Haynes RB, Hanna S, Smith K. Effects of computer-based clinical decision support systems on physician performance and patient outcomes. JAMA 1998:280:1339-46.

6 Montgomery AA, Fahey T. A systematic review of the use of computers in the management of hypertension. I Epidemiol Community Health 1998;52:520-5.

7 StataCorp. Stata Statistical Software: Release 6.0. College Station, TX: Stata Corporation, 1999.

8 Fahey TP, Peters T]. A general practice based study examining the absolute risk of cardiovascular disease in treated hypertensive patients. $\mathrm{Br} \mathrm{J}$ Gen Pract 1996;46:655-70.

9 Donner A, Birkett N, Buck C. Randomization by cluster. Am J Epidemiol 1981;114:906-14.

10 Fahey T, Peters TJ. What constitutes controlled hypertension? A patientbased comparison of hypertension guidelines. BMJ 1996;313:93-6.

11 Ebrahim S. Detection, adherence and control of hypertension for the prevention of stroke: a systematic review. Health Tech Assess 1998;2:1-78.

12 Grimshaw JM, Russell IT. Effect of clinical guidelines on medical practice: a systematic review of rigorous evaluations. Lancet 1993;342:1317-22.

13 Collins R, Peto R. Antihypertensive drug therapy: effects on stroke and coronary heart disease. In: Swales JD, ed. Textbook of hypertension. Oxford: Blackwell Scientific, 1994:1156-64.

14 Hingorani A, Vallance P. A simple computer program for guiding management of cardiovascular risk factors and prescribing. BMJ 1999;318:101-5.

15 Purves I. Prodigy interim report. Newcastle: University of Newcastle, Sowerby Unit for Primary Care Informatics, 1996.

16 Berlowitz D, Ash A, Hickey E, Friedman R, Glickman M, Kader B, et al. Inadequate management of blood pressure in a hypertensive population. N Engl J Med 1998;339:1957-63.

17 Randolph AG, Haynes RB, Wyatt JC, Cook DJ, Guyatt GH for Evidence Based Medicine Working Group. Users' guide to the medical literature. XVIII. How to use an article evaluating the clinical impact of a computerbased clinical decision support system. JAMA 1999-282·67-74.

18 Menard J, Chatellier G. Mild hypertension: the mysterious viability of a faulty concept. J Hypertens 1995;13:1071-7.

19 Haynes B, Haines A. Barriers and bridges to evidence based clinical practice. BMJ 1998;317:273-6.

(Accepted 19July 1999)

\title{
Risk assessment in primary prevention of coronary heart disease: randomised comparison of three scoring methods
}

\author{
Christopher G Isles, Lewis D Ritchie, Peter Murchie, John Norrie
}

Editorial by Jackson

Medical Unit,

Dumfries and

Galloway Royal

Infirmary, Dumfries

DG1 4AP

Christopher G Isles

consultant physician

Department of

General Practice

and Primary Care,

University of

Aberdeen,

Aberdeen

AB25 2AY

Lewis D Ritchie

Mackenzie professor of

general practice

Peter Murchie

clinical research fellow

continued over

BMJ 2000;320:690-1
That lipid lowering with statins benefits even those at low risk of coronary heart disease is no longer open to question. The challenge now is for clinicians to strike a balance between what is desirable, affordable, and achievable. As serum total cholesterol concentration alone poorly predicts cardiovascular risk, alternative methods of risk assessment have been proposed. We compared the ability of general practitioners and practice nurses to interpret three of these methods. We chose the revised Sheffield table, ${ }^{1}$ the New Zealand guidelines, ${ }^{2}$ and the joint British chart $^{3}$ because all three included age, sex, smoking and diabetes status, blood pressure, and ratio of total cholesterol to high density lipoprotein cholesterol as part of their risk assessment.

\section{Subjects, methods, and results}

All 37 general practices in Dumfries and Galloway, in Scotland, were randomised to receive the three risk scores in different sequences, each with the same set of 12 case histories. A self nominated general practitioner and nurse in each practice were each asked whether coronary risk exceeded 3\% per year (Sheffield table), whether it exceeded 30\% over 10 years (joint British chart), or whether cardiovascular risk exceeded $20 \%$ over five years (New Zealand guidelines) for each case history. These thresholds were chosen to reflect current practice. $^{45}$ Doctors and nurses also rated each guideline for ease of use and preference, using scales from 1 to $5(5=$ easiest or most preferred).

Accuracy, ease of use, and preference were compared for doctors and nurses separately, first with Freidman's test overall and then with Wilcoxon's signed rank tests on the differences for each subject for pairs of guidelines. $\mathrm{P}$ values reported are unadjusted for multiple comparisons, but the results stand after correction with the Bonferroni method.

Two practices did not have a practice nurse. In another practice the same nurse did not score all three guidelines, and so the results were excluded from the analyses of ease of use and preference. In all, 33/37 doctors and 22/35 nurses scored at least 10 of 12 case histories correctly when using the Sheffield table; corresponding numbers for the New Zealand guidelines were 37 and 33 respectively and for the joint British chart 36 and 34 respectively. There were no significant differences between the three scores for doctors, whereas accuracy among nurses was significantly poorer 
Comparison of three methods of risk assessment for coronary heart disease among 37 general practitioners and $35^{\star}$ practice nurses. Values in parentheses are approximate $95 \%$ confidence intervals

\begin{tabular}{|c|c|c|c|c|c|c|c|}
\hline \multirow[b]{2}{*}{ Test } & \multirow[b]{2}{*}{ Overall $P$ value } & \multicolumn{2}{|c|}{ New Zealand guidelines $v$ Sheffield table } & \multicolumn{2}{|c|}{ Joint British chart $v$ Sheffield table } & \multicolumn{2}{|c|}{ Joint British chart $v$ New Zealand guideline } \\
\hline & & Median difference & $P$ value & Median difference & $P$ value & Median difference & $P$ value \\
\hline \multicolumn{8}{|l|}{ Doctors: } \\
\hline Accuracy & 0.36 & $0(-0.5$ to 0.5$)$ & 0.48 & $0(0$ to 0.5$)$ & 0.34 & $0(0$ to 0.5$)$ & 1.00 \\
\hline Ease of use & $<0.001$ & 1.5 (1 to 2$)$ & $<0.001$ & $1.5(0.5$ to 2$)$ & $<0.001$ & $0(-0.5$ to 0.5$)$ & 0.63 \\
\hline \multicolumn{8}{|l|}{ Nurses: } \\
\hline Accuracy & 0.002 & $1(0.5$ to 2$)$ & $<0.001$ & $1.5(0.5$ to 2.5$)$ & $<0.001$ & $0(-0.5$ to 0.5$)$ & 0.73 \\
\hline Ease of use & $<0.001$ & $2(1$ to 2.5$)$ & $<0.001$ & $2(1$ to 2.5$)$ & $<0.001$ & $0(-0.5$ to 1$)$ & 0.65 \\
\hline
\end{tabular}

The overall $P$ value is a Friedman test; the pairwise comparisons are Wilcoxon's signed rank tests on the median differences between matched pairs.

*34 for analyses of preference and ease of use (see text).

$(\mathrm{P}<0.001)$ with the Sheffield table than with each of the other two guidelines (table). Only 6 doctors and 6/34 nurses gave the Sheffield table a high preference rating ( 4 or 5 ). More doctors and nurses gave high preference scores for the New Zealand guidelines (26 doctors and 25 nurses) and for the joint British chart (23 and 25) $(\mathrm{P}<0.001$ for the Sheffield table compared with each of the other two guidelines for both doctors and nurses). Similar results were found for ease of use (table).

\section{Comment}

Of these three risk assessment methods, nurses are more likely to interpret correctly the New Zealand guidelines and joint British chart, and both general practitioners and nurses not only find these two methods easier to use but also prefer them to the Sheffield table.

The main strength of our study was that a named general practitioner and nurse within every practice in Dumfries and Galloway completed a formal assessment of each of the three risk scores. A possible limitation is that the study was confined to a single health board. We have no reason to believe, however, that general practitioners and nurses in Dumfries and Galloway are unrepresentative of their colleagues elsewhere in Scotland and the United Kingdom or that the responses would have been different had we assessed the risk scores during clinical contacts.

We have shown that cardiovascular risk assessment by tables and charts based on the Framingham equation is acceptable to both general practitioners and nurses. The results of our study favour the New Zealand guidelines and the joint British chart, the latter of which may be the more suitable for use in primary care. The continuous scale for systolic pressure facilitates assessment of blood pressure and the risk chart is also available as a computer program.

We thank our medical and nursing colleagues in primary care who gave so generously of their time, enabling us to complete this study with such a high response rate; Dr Neil Campbell and Miss Jill Mollison for additional statistical advice; and Mrs Josephine Campbell for her help in preparing the manuscript.

Contributors: CGI, LDR, and JN designed the study. CGI was responsible for its execution. The data were analysed by PM and JN. The paper was written jointly by CGI and LDR, both of whom will act as guarantors.

Funding: None

Competing interests: None declared.

1 Haq IU, Jackson PR, Yeo WW, Ramsay LE. A comparison of methods for targeting CHD risk for primary prevention. Heart 1997;77(suppl 1):36.

2 Dyslipidaemia Advisory Group, on behalf of the Scientific Committee of the National Heart Foundation of New Zealand. 1996 National Heart Foundation guidelines for the assessment and management of dyslipidaemia. N Z Med J 1996;109:224-32.

3 Working Party of the British Cardiac Society, British Hyperlipidaemia Association and British Hypertension Society. Joint British recommendations on prevention of coronary heart disease in clinical practice. Heart 1998;80(suppl 2):S1-29.

4 Winyard G. Standing Medical Advisory Committee statement on the use of statins. London: Department of Health, 1997. (EL(97)41HCD750IP, Aug 1997.)

5 Scottish Intercollegiate Guidelines Network. Lipids and primary prevention of coronary heart disease. Edinburgh: Royal College of Physicians, 1999. (SIGN publication No 40.)

(Accepted 11 November 1999)
Robertson Centre for Biostatistics, Boyd Orr Building, University of Glasgow, Glasgow John Norrie senior statistician

Correspondence to: C G Isles chrisisles@ glebehouse.sol.co.uk

\section{How medicine has changed Mother's milk}

I was due to give a talk entitled "Changes in medicine in 43 years of practice" when I attended the funeral of a patient a few weeks before the presentation. She was a sweet old lady of 96 years who had borne 10 children, and the church was filled to capacity - there were three generations of her family present. An elderly clergyman gave one of the eulogies He related how as a young boy in the 1920s and 1930s he had been a next door neighbour of Ma Smith. In those days, he said, "We didn't have cars, or fridges, or telephones, we never went to the doctor-he didn't have antibiotics or any of the other wonderful medications they have now, and we didn't have health insurance. We only saw the doctor for a broken bone or if dying. Doctors in those days prescribed mustard poultices or the like and Mother knew all about those. One day I got a sore eye. Mother said it was 'pink eye' and it needed warm milk applications. Sometimes we did not have the basics, and at the time we had no milk, so she sent me next door to see Ma Smith. I knocked on her door and when she came I told her my problem. She said, "Look up and hold your eye open child." I did so and she took out her breast and gave me a squirt."

Gordon M Black physician, Pembroke, Bermuda

Ma Smith's treatment may have been soundly based. Breast milk contains a range of antimicrobial proteins, including immunoglobulins, lysozyme, and lactoferrin. Professor John Davis pointed this out to me 37 years ago, noting that West Indian mothers at Hammersmith Hospital frequently treated neonatal sticky eye with breast milk. Roger Robinson BMJ. 